\title{
Smart Power as A Pathway for Employing Sustainable Human Resource Management
}

\author{
Asta Savaneviciene, Zivile Stankeviciute \\ Kaunas University of Technology \\ K. Donelaicio st. 73, LT-44029, Kaunas, Lithuania \\ E-mail.zivile.stankeviciute@ktu.lt; asta.savaneviciene@ktu.lt \\ cross $^{\text {ref }}$ http://dx.doi.org/10.5755/j01.ee.28.2.17645
}

\begin{abstract}
Challenges for human resource management (HRM), such as increased number of work-related illnesses or aging society, require from organizations to rethink the way how people are managed. The most appropriated way relies on the sustainability concept as the axis of sustainability is resource preservation, reproduction and regeneration. The sustainable HRM is designed for enhancing organization's profit, minimizing "ecological footprint" and reducing the harm on employees. However, the employment of sustainable HRM in daily organization's life is still challenging and calls businesses to search for new pathways. The paper argues that smart power (the concept mostly used in political science) could be used for contributing to sustainable HRM field. The paper describes smart power (soft and hard power) and elaborates how smart power could be applied in business context and in the area of sustainable HRM. The paper provides initial insights on power utilization in human resource development, human resource regeneration and human resource preservation practices. The theoretical findings provide some examples how soft and hard power could be used for career management, training programmes for sustainability capacities, and keeping the workforce fit. The use of smart power for work-life balance, management of employees' relations, and stress management is described. In the future, the research area could be expanded by empirically testing theoretical insights and contributing to extremely relevant topic - the use of smart power for employing the sustainable HRM practices.
\end{abstract}

Keywords: Sustainability, HRM, Sustainable HRM, Soft Power, Hard Power, Smart Power.

\section{Introduction}

Challenges on economic (financial crisis; continually growing consumption), ecological (climate changes, pollution) and social (aging society, labour force shortage) levels call for the shift in mankind's approaches and activities. The agreement on the scientific level (Baumgartner \& Rauter, 2017) and the political level (at the United Nations Sustainable Development Summit on 25 September 2015 more than 150 world leaders adopted the new 2030 Agenda for Sustainable Development) provides strong evidence that business is responsible for sustainable development. However, business commitment to sustainability means that the "triple bottom line" - economic, social and environmental pillars (Elkington, 1997) should be reflected in all functions, including HRM. Moreover, organizations are worried about worldwide changes concerning quality and quantity of human resources (Mariappanadar, 2014a, 2014b; Ehnert, 2009a). Hereby, incorporation of sustainability in HRM is a "survival strategy", enabling to maintain, regenerate and develop human resources.

In the past decade an increase in publications on sustainable HRM (De Prins et al., 2014; Ehnert et al., 2014; Harry, 2014; Ehnert \& Harry, 2012; Kramar, 2014; Mariappanadar, 2012a, 2012b, 2014a; Gollan \& Xu, 2014; Maley, 2014; Suriyankietkaew \& Avery, 2014; Kozica \& Kaiser, 2012; Sotome \& Takahashi, 2014) has been obvious. However, scholars focus mainly on general aspects of sustainable HRM or on the models of sustainable HRM. The pathways how to employ sustainable HRM in daily people management and to reach the value for different stakeholders are not well explored.

The aim of the paper is to disclose how smart power could be used for employing sustainable HRM.

The paper contributes to the body of literature on sustainable HRM in several ways. Firstly, the paper introduces a fresh approach in the search for the answer how can the employment of sustainable HRM be supported? Secondly, the paper describes the concept of smart power and elaborates how it could be applied for business. Thirdly, the insights how smart power could be used for employing sustainable HRM are provided. The intention is not to introduce a comprehensive framework. On the contrary, the paper endeavours to contribute to the body of literature by providing some initial theoretical insights on one pathway (in that case using the smart power construct) for employing bedding sustainable HRM.

The paper is organized as follows. It starts with sustainability idea and defines the construct of sustainable HRM. Later paper focuses on smart power, describes soft and hard power and the scope of power use for business. Further, insights concerning smart power use for sustainable HRM are provided. At the end of the paper the conclusions are presented. 


\section{Sustainability as A Concept for HRM}

The idea of sustainability was known already in the time of Aristotle (Ehnert, 2009a), however until the late 1970s the notion was employed only occasionally (Leal Filho, 2000) and primarily used with reference to environmental politics. However, in the light of social inequity, unequal access for all people to resources and continuing large scale consumption of goods or services in industrialized countries (Zink, 2014; Ehnert et al., 2014), the concern of advancement of the societal and economic development without endangering natural living conditions becomes the main topic. A significant step forward towards acknowledgment of the importance of sustainability was done by World Commission on Environment and Development (WCED), defining sustainable development as "development that meets the needs of the present without compromising the ability of future generations to meet their own needs" (WCED, 1987, 43).

As proposed by Elkington (1997), business sustainability means adopting "triple bottom line" approach focusing on economic, social and environmental performance. It is worth to highlight the intersection of environmental integrity, economic prosperity and social equity principles - if any one of these principles is not observed, sustainability will not be achieved (Bansal, 2005; Dyllick \& Hockerts, 2002). The unspoken assumption of the business" "bottom line" - "the more the better and the bigger the more successful" (Laszlo et al., 2010) - is denied, if business votes for sustainable decisions.

In terms of sustainability on HRM level, a review of scientific literature reveals a conflicted situation. On the one hand, human resources and their management are acknowledged as essential sources for an organization's success (Wright et al., 2005). On the other hand, organizations do not pay enough attention and do not apply policies and means enabling protection of human resources from negative externalities (Mariappanadar, 2014a, 2014b).

The literature review allows to state that the research linking sustainability and HRM is emerging under different labels, however the main construct is sustainable HRM (De Prins et al., 2014; Ehnert, 2006, 2009a, 2009b, 2010, 2011, 2012, 2014; Guerci et al., 2014; Kramar, 2014; Zaugg et al., 2001; Thom \& Zaugg, 2002; Zaugg, 2009; Mak et al., 2014; Guerci \& Pedrini, 2014).

The literature on sustainable HRM still raises a question associated with definition of the construct (Kramar, 2014). One of the most popular definitions, provided by Ehnert (2009a), acknowledges the organization's obligation not only to effectively use human resources, but also to ensure the supply of these resources in the future. Hereby, a duality of the organization's goals is reflected. The definition underlines a long-term perspective and integration of short- and longterm goals. It recognises that some stakeholders (mainly employees) will lose as a result of HRM. The definition provided by Ehnert (2009a) points out the dynamic aspect of sustainable HRM, as sustainability does not mean stability or longevity (Kira \& Lifvergren, 2014; Guerci et al., 2014).

Although the term sustainable HRM can be conceptualized in a variety of ways (Ehnert, 2009a; Kramar, 2014; Taylor \& Lewis, 2014), in that paper sustainable HRM refers to HRM that enhances profit maximization for the organization and also 'reduces the harm' on employees, their families and communities. (Mariappanadar, 2014a, 2014b). Sustainable HRM underlines the synthesis effect, arguing that organizations can maximize their profit through HRM practices, as well as reduce the harm of HRM practices on employees, because these two polarities are not mutually exclusive, but mutually reinforcing (Mariappanadar, 2014b; Mariappanadar \& Kramar 2014). However, linking sustainability to HRM is relevant in analysing how HRM practices could be employed implied to minimize the harm. What managerial solutions could be used for employing sustainable HRM? One of the possible pathways relies on smart power construct.

\section{Smart Power for Business Context}

The paper starts with a general overview of smart power and later moves towards the insights how the concept could be translated for business context.

The concept of power is a contested concept (as sustainability): there is no single definition accepted on scientific, political, economic or managerial levels. As power implies causation, the paper follows the definition provided by Nye (2011), stating that power is "the capacity to do things, but more specifically in social situations we are interested in the ability to affect others to get the outcomes one wants" (p. 10-11). Power could be defined in terms of resources and in terms of behaviour (Nye, 2008a, 2011).

Behavioural definitions measure power by the outcomes, which are determined after the action rather than before the action, so ex post is perceived as more relevant as ex ante. Power defined as resources encompasses resources that can produce outcomes. In terms of a country, these resources could encompass large population, territory, natural resources or military force. If power is defined as resources, it appears to be concrete, measurable, and predictable, therefore, sometimes the preference is given to resources defining power as synonymous with the resources. However, the resources of power do not guarantee the achievement of the desired outcomes (Nye, 2011). Hereby, the meaningful argument of Nye (2011) that "Converting resources into realized power in the sense of obtaining desired outcomes" (p. 12) requires consideration and implementation.

Two forms of power could be distinguished: soft power and hard power (Nye, 2008a, 2011; Gallarotti, 2015). According to Nye (2011), soft power is "the ability to affect others to obtain preferred outcomes by the co-opted means of framing the agenda, persuasion, and positive attraction". (p. 19). Soft power rests on the ability to shape the preferences of others (countries, organizations, and people) without the use of coercion or violence (Nye, 2008a). Soft power is about the ability to attract people. Soft power relies on this phrase: "If I can get you to want to do what I want, then I do not have to force you to do what you do not want." (Nye, 2008a, p. 95). Soft power is the capacity to persuade others to do what one wants (Wilson, 2008).

Hard power is the capacity to coerce others to do what one wants (Wilson, 2008). Hard power is the capacity to get what one wants through the use of economic power, military force or by threatening to use economic superiority or coercive capacities. 
As regards the spectrum of power behaviours, moving from the hard power towards the soft power the behaviours are arranged in the following spectrum (Nye, 2011):

Command / coerce, threat, pay, sanction, frame, persuade, attract/ Co-opt

It is relevant to highlight that behaviours in the spectrum sometimes overlap, but they can be conceived in terms of the degree of voluntarism (Nye, 2011). Hard power is based on command behaviour, it uses force and payment, in some cases agenda setting and framing. Meanwhile, agenda setting and framing that is regarded as legitimate by the target, positive attraction, and persuasion are the parts of the spectrum of behaviours in soft power (Nye, 2011). Hard power rests on inducements ("carrots") or threats ("stick"), while soft power rests on attraction (Nye, 2008a). Command power is very visible in comparison to soft power, which is less visible (Nye, 2011).

As regards the power resources, in general, soft power often includes intangible factors, such as institutions, ideas, values, culture, and perceived legitimacy of policies. Meanwhile, hard power usually includes tangible resources, such as force and money (Ney, 2011). However, one tricky aspect remains- resources often associated with hard power behaviour can also produce soft power behaviour (and vice versa), depending on the context and how they are used (Nye, 2011). According to Heywood (2014), the effectiveness of soft and hard power approaches depends on the accessibility of power resources.

Gallarotti (2015) supports Nye (2011), arguing that hard power demonstrates a greater conflict of interests relative to soft power. Cooper (2004) reveals the difference between hard and soft power, arguing that "at the core of soft power is legitimacy" (p. 8).

Nye (2008a, 2008b, 2011) incorporates two forms of power in the construct of Smart Power. According to Nye (2008b), "Smart power is the ability to combine the hard power of coercion or payment with the soft power of attraction into a successful strategy" (p. 6). Wilson (2008) treats smart power as "the capacity of an actor to combine elements of hard power and soft power in ways that are mutually reinforcing such that the actor's purposes are advanced effectively and efficiently“(p. 115) (Figure 1).

\section{SMART POWER - POLITICAL PERSPECTIVE (based on Nye, 2011)}

$$
\begin{aligned}
& \text { Soft power in terms of behaviour } \\
& \text { Frame, persuade, attract }
\end{aligned}
$$

Soft power in terms of resources

Institutions, ideas, values, culture, perceived legitimacy of policies

\section{Hard power in terms of behaviour}

Coerce, threat, pay, sanction, framing

Hard power in terms of resources

Money, force

Figure 1. Smart Power from a Political Perspective

Interpreting smart power as a concept which could be translated for business, the questions are related to appropriated power resources and power behaviour, so what kind of power and how could be employed implied for business context?
Organizations can opt only for soft or hard power, or use smart power striving for a long-term survival In order to affect the behaviour of stakeholders by shaping preferred outcomes, "carrots", "sticks" or attraction could be chosen by businesses. Some examples are provided in Figure 2.

SMART POWER - BUSINESS PERSPECTIVE (own elaboration)

Soft power in terms of behaviour

Change of products or services; change of work organization; negotiation based on equal positions

\section{Soft power in terms of resources}

Ideas, values, organization culture, perceived legitimacy of organization's policies

\section{Hard power in terms of behaviour}

Economic sanctions; "Buying" practice; negotiation based on unequal positions

Money; economic force

Figure 2. Smart Power from a Business Perspective

Coercion is quite difficult to imagine in democratic countries, especially in business relations with consumers, due to the institutional context (law, regulations, culture, etc.). However, economic and physical coercion could be found in some non-democratic countries, where appears to be no choice or a certain degree of choice in business activities or contracts, following a well-known expression "your money or your life".
As regards the economic measures, pay and sanctions could be applied for business context. Inducement is about economic superiority; it can be positive and negative (sanctions). However, positive perspective is usually shortterm oriented, as it is related to capacity to "buy" other business organizations, while "any payment can easily be turned into a negative sanction by the implicit or explicit threat of its removal"(Nye, 2011, p. 14). Hereby, in the 
above-mentioned case of the use of hard power businesses deny a long-term orientation as one of the sustainability's principles. Generally, businesses use economic sanctions in two cases: in order to ensure the execution of the agreement or "pushing" others to change their initial preferences. The second case reflects the use of hard power and contradicts the idea of sustainability. By the way, in regards of economic superiority, unequal bargaining relationships could be emphasized, as some organizations apply "take it or leave it" strategy to the people who have limited choice.

Framing and agenda setting is called "second face of power", referring that "If one can use ideas and institutions to frame the agenda for action in a way that makes others' preferences seem irrelevant or out of bounds, then it may never be necessary to push or shove them" (Nye, 2011). Thus, businesses can form the preferences of stakeholders by affecting their expectations of what is feasible or legitimate (Nye, 2011). For example, one organization can affect another organization during negotiations, convincing it that some new products will have no demand among generation $\mathrm{Z}$.

Persuasion and attraction relies on shaping the others' initial preferences. There are two possible pathways: first, by changing the situation, second, by determining the wants (Nye, 2011). Employing the first pathway means that organization uses the power over consumer by getting this costumer to do what he/she would not want to do otherwise. Two examples illustrate the situation. The organization stops producing its favourite chocolate to encourage consumers to buy another chocolate. According to the second pathway, organizations launch a huge advertising campaign to determine if working people feel the need to enjoy a cup of coffee every morning.
The above-mentioned examples show how businesses can use soft or hard power, however it is worth reminding that hard and soft power could reinforce each other - striving for better performance, businesses can determine the wants of other organization and also use sanctions.

Although human resources are considered a critical factor for business success, the management of these resources is still challenging (Pffefer, 2010; Marriapanadar, 2012a, 2012b, 2014a, 2014b). As HRM can cause not only positive outcomes, but also the harm to employees, their family members and society, a sustainable HRM refers to HRM that reduces the harm. While smart power allows finding solutions to meet businesses' aspirations, it raises a question of how smart power can be used for employing sustainable HRM.

\section{Smart Power for Sustainable HRM Practices}

We limit our discussion to the use of soft and hard power by implementing sustainable HRM practices. It means that our insights do not cover HRM practices which do not address employee wellbeing.

The axis of sustainability concept is preservation, regeneration and development of resources. In order to preserve, regenerate and develop human resources, appropriate HRM practices are employed. Undoubtedly, some practices overlap and can be applied for the achievement of two or even three targets. We focus on the use of smart power by providing some examples from the field of HRM practices, aimed at development, regeneration and preservation of people (Figure 3 ).

\begin{tabular}{|c|c|}
\hline \multicolumn{2}{|c|}{ SMART POWER - SUSTAINABLE HRM PERSPECTIVE (own elaboration) } \\
\hline $\begin{array}{l}\text { Soft power in terms of behaviour } \\
\text { Rotation; employees' substitution; encouragement of employees; } \\
\text { consultation on issues and training; stimulating of the new fields of } \\
\text { employee's interest; various learning forms; rewards; linking of } \\
\text { green initiatives with HRM practices; provision of information; } \\
\text { supporting of "work in office" culture }\end{array}$ & $\begin{array}{l}\qquad \text { Hard power in terms of behaviour } \\
\text { Penalties for employees; refusal of rewards for employees; } \\
\text { "buying" practices; force according to law; dismissal }\end{array}$ \\
\hline $\begin{array}{l}\quad \underline{\text { Soft power in terms of resources }} \\
\text { Code of conduct; values; organization culture; perceived legitimacy } \\
\text { of organization's policies }\end{array}$ & $\begin{array}{r}\text { Hard power in terms of resources } \\
\text { Money; economic force, force set in law }\end{array}$ \\
\hline
\end{tabular}

Figure 3. Smart Power from a Sustainable HRM Perspective

Human resource development. Sustainability requires paying more attention to learning and development, as investment in the development of human resources strengthens organizations (Harry, 2014). It is necessary, although not sufficient to develop competencies the employees need now, while it is essential to set and develop future skills and capabilities. Hereby, development for today and for tomorrow under changing conditions (Osranek \& Zink, 2014) is the cornerstone if the business is really concerned about sustainability.

Becker (2011) suggests for businesses to answer two questions, which allow identification of the prevailing attitudes and practices in the field of development. The first part of the questions corresponds to unsustainable approach; the second part of the questions is suitable for sustainability idea. The first question is the following: do you buy a talent on the market or create flexibility through postponement? If a business observes sustainability, it gives employees the possibility to develop their full potential in the long-term and across a variety of jobs, using different strategies, such as job rotation. It is essential to perceive the value provided by long-term development orientation, as long-term orientation allows employees to learn functions outside their own divisions. Hereby, a manager acquires an understanding about core value-adding process in all divisions; meanwhile cross-trained employees contribute to the process of the 
organizations' adaptation to uncertainly (Becker, 2011). The answer to the second question allows finding out if organizations look for a free ride, or development of a supply chain surplus of talent. Free riding means that organizations take advantage of the training efforts of others without sharing the cost. Sustainability approach is employed when organizations support each other by coordinating training programs, building collaborative relationships with education institutions or participating in professional networks (Becker, 2011).

Human resource development is implemented using different HRM practices, such as career management, competence development, talent management, mentoring, life-long learning or training programmes aimed at development of capacities for a more sustainable development. The question is, does smart power enable application of these practices in the organizations, aiming to minimize the harm on employees? We will provide some insights on the question by exploring career management and training programmes for sustainability capacities.

Career management. Expanding career through a sustainability lens provides a new career concept, including four elements: time, social space, agency and meaning (Van der Heijden \& De Vos, 2015). Continuity over time means that periods of full-time employment can interchange with periods of unemployment, volunteering, childcare, studies, part-time employment or others. Social space implies that careers are possible within and across different contexts, such as work, home or non-governmental organizations. Agency indicates that how a career develops over time is the result of a lot of choices made by individuals; hereby different values are related to different career outcomes (Van der Heijden \& De Vos, 2015). The above-mentioned four elements imply that sustainable career management is only possible, if employee and employer interact. On the basis of interaction and common actions perspective, Valcour (2015) introduces 4 attributes from the perspectives of employee and employer (put into pairs) that characterize a sustainable career. Based on these pairs of attributes, the paper analyses the use of smart power.

The first pair of attributes: Alignment of work with individual's strengths, interests and values (employee's perspective) corresponds to maximum yield on human capital value (employer's perspective). If a business seeks to align work with employees' strengths and interests, it seems that soft and / or hard power could be useful. By employing organizational culture as a resource of soft power, the organization can persuade and attract employees to the new field of interest related to new skills and competencies complying with strategic goals of the business. For example, sport activities supported by organizational culture can shape the employee's preferences for team work. The belief that learning is a value in itself could be created by changing the situation at work, performing the tasks according to the standards of quality management. As regards the hard power, the organization can "buy" an employee with the use of economic power superiority, asking to change his/her interests or values. Even in the short-term perspective, an employee can be happy due to a "reward", however the longterm benefit and value of such "reward" for both stakeholders is debatable.
The second pair of attributes: Ongoing learning and renewal corresponds (employee's perspective) to continuous updating of organizational competencies (employer's perspective). Striving to update competencies, a business can use soft and / or hard power. The soft power can be applied by changing the employee's position (rotation, substitution due to illness), hereby a changed situation encourages employees to learn new skills. Organization can influence and determine the employees' desire for permanent learning by providing various learning forms, such as online training, mentoring, on-the-job training or internships. The initial wish to learn could be shaped by implementing a reward strategy related to ongoing learning and acquisition of new competencies. Hard power is expressed in removal of bonuses based on the lack of acquired new skills during a defined period of time. Hard power manifests when evaluation process includes the employer's requirement for the employees to update their skills, creating a threating atmosphere, as learning could be linked to less responsibility, less money or even dismissal. In terms of sustainability, dismissal could be used after exploring all chances and choices for the continuity of employment.

The third pair of attributes: Security via employability (employee's perspective) with stability via adaptability (employer's perspective). While seeking employability, it seems useful not to focus on a specific profession, but rather seek to get a generally high "market-value" in the labour market and engage in continuous development (Zaugg et al., 2001). Employees' ability to adapt to changes leads to stability even in the changing situation of the market. Businesses striving for stability via adaptability can use power in a similar way as provided in the previous paragraph.

The fourth pair of attributes: Work-life pertinence during life relates to organizational commitment and retention. As the topic of work-life balance is discussed in more detail in the exploration of the employees' preservation, here we only emphasize a business' capability to shape the preferences of employees by defining an "ideal worker" - someone, who is expected to work long hours, give priority to work over other areas of life or avoid career breaks (Valcour, 2015).

Training programmes for sustainability capacities. According to Harry (2014), a particular focus in development field should be given to capabilities of more sustainable development. Training on environmental sustainability, teaching to handle safety issues at work, cope with stress or balance work and private life should be a part of the employee's development strategy. Tangible or intangible power resources can serve for implementation of training programmes. For example, money could be used in the form of penalties for non-compliance with targets in environmental management (Renwick, Redman \& Maguire, 2008). The ideas, values, culture or perceived legitimacy of environmental policies could serve for framing, persuasion and attraction of employees. The above-mentioned resources could be used to encourage employees to use green transportation or link participation in Green initiatives to promotion/career achievements (Renwick et. al, 2008).

Regeneration of employees. Human resources, like any other resources, can be exploited or their regeneration ability 
can be damaged. Various sustainable HRM practices could be used for regeneration of employees: ergonomic work conditions, occupational safety and health, keeping the workforce fit and so on. The paper focuses on keeping the workforce fit, as occupational safety and health is strongly related to legal regulations; ergonomic work conditions are also based on the requirements of the law.

Keeping the workforce fit. These practices rely on health programmes for employees, fostering physical activities, healthy nutrition, breaks and physical exercises during working days, etc. Businesses can change the preferences of employees in terms of leading unhealthy lifestyle (no sport activities) using hidden and invisible faces (Nye, 2011). For example, a launched advertising campaign of the sport club located near the organizations' premises could be used to encourage employees to be physically active. The desire of businesses to have fit employers could be achieved when soft power is reinforced by hard power. For example, a healthy lifestyle could be promoted by paying 50 percent less bonus to the employees leading unhealthy lifestyle.

Preservation of employees. According to MerriamWebster, the term "sustainable" refers to the ability to be used without being depleted or destroyed (Van der Heijden \& De Vos, 2015), hereby preservation of employees is one of cornerstones of sustainable HRM. Various practices can be used to minimize the harm on employees: work-life balance, management of employees' relations, management of work-related stress, workload management, diversity management, etc. The paper focuses on work-life balance, management of employees' relations, stress management, and examines the use of smart power.

Work-life balance. According to Zaugg et al. (2001), though work is still considered essential to most employees, private life is seen as equally valuable. Rowan (2000) argues that "there is no reason for thinking that business life must be opposed to (and thus cannot contribute to) personal life" (p. 358). Dual-career families, high work demands and long working hours (Kinman \& McDowall, 2009) indicate that the line between two social roles - a person and a specialist - disappears. To combine work and family life businesses introduce various initiatives, as time related, informational, financial or direct support (Hoeppe, 2014). Smart power could be applied enabling employees to combine work and private life. Furthermore, the use of hard power is obvious while seeking sustainability of human resources. Command power could be expressed in the organization's regulations (law) indicating that employees have to leave the workplace (premises) until the certain time and then electricity is switched off. As a result of hard power, no payment is provided for the employees' results that are achieved while working overtime. Fostering "work only in the office, do not do work-related tasks at home" culture (no emails 5 minutes before the end of the working day, requesting to provide data till 23.59) could shape the employees' preferences to stop competing for a label of the "worker, who sends workrelated emails during the night".

Management of employees' relations. Based on the tournament theory (Lazear, 1989), Brown and Shields (2011) emphasize that workers in the environment which fosters competition face a desire to undermine their colleagues. Hereby, cooperation of employees is in line with sustainability approach. Cooperation provides additional value to the business' performance, as well as reflects in good relations of employee's and good relations between employee and line manager. Cooperation between employees could be strengthened by changing the situation, for example, replacing individual work with team work, and introducing a team reward system. "Code of conduct", as part of the organization culture, could be used for management of employees' relations. The employee's perception that they and their duties are interdependent could be fostered using soft power (for example, rotation, providing information on activities of other workers) or hard power (penalty for a delayed fulfilment of duties).

Management of work-related stress. European Commission underlines that stress, is "a state, which is accompanied by physical, psychological or social complaints or dysfunctions and which results from individuals feeling unable to bridge a gap with the requirements or expectations placed on them" (p. 16). Hereby, the stress is considered a structural issue affecting each employee. According to Ongori \& Agolla (2008), work-related stress is defined as a perception of discrepancy between environmental demands (stressors) and individual capacities to meet these demands. Seeking to minimise work-related stress, soft power could be applied most often. As soft power is a pull (Nye, 2011), businesses can hire a specialist who deals with stress issues or organize training for stress management. Consultations by specialist or training could shape the preferences of employees, teaching them how to cope with stress.

Summing up, the provided examples reveal that striving to minimize the harm on employees the organizations can use soft and / or hard power. The synergy of soft and hard power could provide better results and allow continuing business' journey to sustainable organization.

\section{Conclusions}

Linking sustainability and HRM is related to constantly increasing challenges inside and outside the organizations. The challenges directly or indirectly affect the quality and the quantity of human resources. Sustainability is chosen for HRM due to its potential to overcome troubles and develop, to regenerate and preserve human resources. Sustainable HRM points out the synthesis effect arguing that organizations can maximize their profit through HRM practices, as well as reduce the harm of HRM practices on employees, because these two polarities are mutually reinforcing.

The paper argues that one of the pathways for employing sustainable HRM is the use of smart power - the ability to combine the hard power of coercion or payment with the soft power of attraction. Business can opt only for soft or hard power, or employ smart power striving for sustainability. Seeking to affect the behaviour of stakeholders by shaping preferred outcomes, "carrots", "sticks" or attraction could be chosen by businesses.

Exploring how smart power could be applied for sustainable HRM, the practices from the field of employees' development, regeneration and preservation are chosen. The paper provides the ideas related to the use of power, which covers the following HRM practices: career management, training programmes for sustainability capacities, keeping 
the workforce fit, work-life balance, management of employees' relations and management of work-related stress. The examples reveal that striving to employ sustainable HRM, businesses can use soft and / or hard power; the synergy is reached by smart power.
Recommendations for the future are related to the empirical testing. The research area could be expanded by empirical testing of theoretical insights on the use of smart power in the organizations striving to employ sustainable HRM and contribute to creation of sustainable business organization.

\section{References}

Bansal, P. (2005). Evolving sustainably: longitudinal study of corporate sustainable development. Strategic Management Journal, 26 (3), 197-218. https://doi.org/10.1002/smj.441

Baumgartner, R. J., \& Rauter, R. (2017). Strategic perspectives of corporate sustainability management to develop a sustainable organization. Journal of Cleaner Production, 140, 81-92. https://doi.org/10.1016/j.jclepro.2016.04.146

Becker, W. S. (2011). Are you leading a socially responsible and sustainable human resource function? People \& Strategy, 34 (1), 18-23.

Brown, M., \& Shields, J. (2011). Reward management: rethinking individual performance pay. In Clarke M. (Ed.), Readings in HRM and Sustainability (pp. 64-81). Tilde University Press.

Cooper, R. (2004). Hard power, soft power and the goals of diplomacy. American power in the 21st century, 167-180.

De Prins, P., Van Beirendonck, L., De Vos, A., \& Segers, J. (2014). Sustainable HRM. Bridging theory and practice trough the Respect Opennes Continuity (ROC)-model. Management Review, 25 (4), 244-284.

Dyllick, T., \& Hockerts, K. (2002). Beyond the business case for corporate sustainability. Business Strategy and the Environment, 11 (2), 130-141. https://doi.org/10.1002/bse.323

Ehnert, I. (2006). Sustainability issues in human resource management: linkages, theoretical approaches, and outlines for an emerging field. Paper prepared for 21st EIASM SHRM Workshop, Aston, Birmingham, March 28th-29th, 2006.

Ehnert, I. (2009a). Sustainable human resource management: A conceptual and exploratory analysis from a paradox perspective. Heidelberg: Physica-Verlag. https://doi.org/10.1007/978-3-7908-2188-8

Ehnert, I. (2009b). Sustainability and human resource management: reasoning and applications on corporate websites. European Journal of International Management, 3 (4), 419-438. https://doi.org/10.1504/EJIM.2009.028848

Ehnert, I. (2010). Nachhaltigkeit im HR-Management: Spannungen aushalten, Widerspruche bewaltigen. Personalfuhrung, $42(5), 26-36$.

Ehnert, I. (2011). Sustainability and human resource management: a model and suggestions for future research. In A. Wilkinson, \& K. Townsend (Eds.), The future of employment relations, (pp. 215-237). Palgrave.

Ehnert, I. (2012). Nachhaltiges Personalmanagement: Konzeption und Implementierungsansätze. In S. Kaiser, \& A. Kozica (Eds.), Ethik im Personalmanagement: Zentrale Konzepte, Ansatze und Fragestellungen, (pp. 131-157). Munchen Mering: Hampp.

Ehnert, I. (2014). Paradox as a Lens for Theorizing Sustainable HRM. In I. Ehnert, W. Harry, \& K.J. Zink (Eds.), Sustainability and Human Resource Management. Developing sustainable business organizations, (pp. 247-271). Berlin Heidelberg: Springer. https://doi.org/10.1007/978-3-642-37524-8_11

Ehnert, I., \& Harry, W. (2012). Recent developments and future prospects and sustainable human resource management: Introduction to the special issue. Management Review, 23 (3), 221-238.

Ehnert, I., Harry, W., \& Zink, K. J. (2014). Sustainability and HRM. In I. Ehnert, W. Harry, \& K.J. Zink (Eds.), Sustainability and Human Resource Management. Developing sustainable business organizations, (pp. 3-32). Berlin Heidelberg: Springer. https://doi.org/10.1007/978-3-642-37524-8_1

Elkington, J. (1997). Cannibals with forks: The Triple Bottom Line of 21st century business, Oxford: Capstone Publishing Ltd.

European Commission (2011). Report on the implementation of the European social partners' Framework Agreement on Work-related Stress. [2014-10-12]. http://erc-online.eu/wp-content/uploads/2015/03/COM_SEC20110241_EN.pdf

Gallarotti, G. M. (2015). Smart power: definitions, importance, and effectiveness. Journal of Strategic Studies, 38(3), 245281. https://doi.org/10.1080/01402390.2014.1002912

Gollan, P. J., \& Xu, Y. (2014). Fostering corporate sustainability. Sustainability and HRM". In I. Ehnert, W. Harry, \& K.J. Zink (Eds.), Sustainability and Human Resource Management. Developing sustainable business organizations, (pp. 225-245). Berlin Heidelberg: Springer. https://doi.org/10.1007/978-3-642-37524-8_10

Guerci, M., Shani, A. B. (Rami), \& Solari, L. (2014). A stakeholder perspective for sustainable HRM. In I. Ehnert, W. Harry, \& K.J. Zink (Eds.), Sustainability and Human Resource Management. Developing sustainable business organizations, (pp. 205-223). Berlin Heidelberg: Springer.

Guerci, M., \& Pedrini, M. (2014). The consensus between Italian HR and sustainability managers on HR management for sustainability - driven change- towards a "strong" HR management system. The International Journal of Human Resource Management, 25 (13), 1787-1814. https://doi.org/10.1080/09585192.2013.860388 
Hahn, T., \& Figge, F. (2011). Beyond the bounded instrumentality in current corporate sustainability research: toward an inclusive notion of profitability. Journal of Business Ethics, 104, 325-345. https://doi.org/10.1007/s10551-0110911-0

Harry, W. (2014). The relevance of the vision of sustainability to HRM practice. In Ehnert, I., Harry, W., \& Zink, K.J. (2014a). Sustainability and HRM. In I. Ehnert, W. Harry, \& K.J. Zink (Eds.), Sustainability and Human Resource Management. Developing sustainable business organizations, (pp. 401-419). Berlin Heidelberg: Springer. https://doi.org/10.1007/978-3-642-37524-8_18

Heywood, A. (2014). Global politics. Palgrave Macmillan. https://doi.org/10.1007/978-1-137-34927-9

Hoeppe, J. C. (2014). Practitioner's view on sustainability and HRM. In I. Ehnert, W. Harry, \& K.J. Zink (Eds.), Sustainability and Human Resource Management. Developing sustainable business organizations, (pp. 273-294). Berlin Heidelberg: Springer. https://doi.org/10.1007/978-3-642-37524-8_12

Kinman, G., \& McDowall, A. (2009). Does work/life balance depend on where and how you work? EAWOPinPractice, 3 , $3-10$.

Kira, M., \& Lifvergren, S. (2014). Sowing seeds for sustainability in work systems. In I. Ehnert, W. Harry, \& K.J. Zink (Eds.), Sustainability and Human Resource Management. Developing sustainable business organizations, (pp. 5781). Berlin Heidelberg: Springer. https://doi.org/10.1007/978-3-642-37524-8_3

Kozica, A., \& Kaiser, S. (2012). A sustainability perspective in flexible HRM: how to cope with paradoxes of contingent work. Management Review, 23 (3), 239-261.

Kramar, R. (2014). Beyond strategic human resource management: is sustainable human resource management the next approach?. The International Journal of Human Resource Management, 25 (8), 1069-1089. https://doi.org/10. 1080/09585192.2013.816863

Laszlo, A., Laszlo, K. C., \& Dunsky, H. (2010). Redefining success: designing systemic sustainable strategies. Systems Research and Behavioral Science, 27 (1), 3-27.

Leal Filho, W., (2000). Dealing with misconceptions on the concept of sustainability. International Journal of Sustainability in Higher Education, 1 (1), 9-19. https://doi.org/10.1108/1467 630010307066

Mak, A., Cheung, L., Mak, A., \& Leung, L. (2014). Confucian thinking and the implications for sustainability in HRM. Asia-Pacific Journal of Business Administration, 6 (3), 206-224. https://doi.org/10.1108/apjba-02-2014-0029

Maley, J. (2014). Sustainability: the missing element in performance management. Asia-Pasific Journal of Business Administration, 6 (3), 190-205. https://doi.org/10.1108/APJBA-03-2014-0040

Mariappanadar, S. (2012a). Harm of efficiency oriented HRM practices on stakeholders: an ethical issue for sustainability. Society and Business Review, 7 (2), 168-184. https://doi.org/10.1108/17465681211237628

Mariappanadar, S. (2012b). The harm indicators of negative externality of efficiency focused organizational practices. International Journal of Social Economics, 39 (3), 209-220. https://doi.org/10.1108/03068291211199378

Mariappanadar, S. (2014a). The model of negative externality for sustainable HRM". In I. Ehnert, W. Harry, \& K.J. Zink (Eds.), Sustainability and Human Resource Management. Developing sustainable business organizations, (pp. 181203). Berlin Heidelberg: Springer. https://doi.org/10.1007/978-3-642-37524-8_8

Mariappanadar, S. (2014b). Stakeholder harm index: a framework to review work intensification from the critical HRM perspective. Human Resource Management Review, 24, 313-329. https://doi.org/10.1016/j.hrmr.2014.03.009

Mariappanadar, S., \& Kramar, R. (2014). Sustainable HRM: The synthesis effect of high performance work systems on organisational performance and employee harm. Asia-Pacific Journal of Business Administration, 6 (3), $206-224$. https://doi.org/10.1108/APJBA-03-2014-0039

Nye Jr, J. S. (2008). Smart Power and the "War on Terror". Asia Pacific Review, 15(1), 1-8. https://doi.org/10.1080/ 13439000802134092

Nye, J. S. (2008). Public diplomacy and soft power. The annals of the American academy of political and social science, 616(1), 94-109. https://doi.org/10.1177/0002716207311699

Nye, J. S. (2011). Power and foreign policy. Journal of political power, 4(1), 9-24. https://doi.org/10.1080/ 2158379X.2011.555960

Ongori, H., \& Agolla, J. E. (2008). Occupational stress in organizations and its effects on organizational performance. Journal of Management Research, 8 (3), 123-135.

Osranek, R., \& Zink, K. J. (2014). Corporate human capital and social sustainability of human resources. Towards an integrative measurement framework. In I. Ehnert, W. Harry, \& K.J. Zink (Eds.), Sustainability and Human Resource Management. Developing sustainable business organizations, (pp. 105-126). Berlin Heidelberg: Springer. https://doi.org/10.1007/978-3-642-37524-8_5

Pfeffer, J. (2010). Building sustainable organizations: the human factor. Academy of Management Perspectives, 24(1), 3445. https://doi.org/10.5465/AMP.2010.50304415

Renwick, D. W. S., Redman, T., \& Maguire, S. (2013). Green human resource management: a review and research agenda. International Journal of Management Review, 15, 1-14. https://doi.org/10.1111/j.1468-2370.2011.00328.x 
Rowan, J. R. (2000). The moral foundation of employee rights. Journal of Business Ethics, 24 (4), $355-361$. https://doi.org/10.1023/A:1006286315756

Sotome, R., \& Takahashi, M. (2014). Does the Japanese employment system harm productivity performance? A perspective from DEA-based productivity and sustainable HRM. Asia-Pacific Journal of Business Administration, 6(3), 225246. https://doi.org/10.1108/APJBA-02-2014-0031

Suriyankietkaew, S., \& Avery, G. C. (2014). Leadership practices influencing stakeholder satisfaction in Thai SMEs. AsiaPacific Journal of Business Administration, 6 (3), 247-261. https://doi.org/10.1108/APJBA-01-2014-0010

Taylor, S., \& Lewis, C. (2014). Sustainable HRM in US. The influence of national context. In I. Ehnert, W. Harry, \& K.J. Zink (Eds.), Sustainability and Human Resource Management. Developing sustainable business organizations, (pp. 297-314). Berlin Heidelberg: Springer. https://doi.org/10.1007/978-3-642-37524-8_13

Thom, N., \& Zaugg, R. J. (2002). Das Prinzip Nachhaltigkeit im Personalmanagement. Personalfuhrung, (7), 52-55.

Valcour, M. (2015). Facilitating the crafting of sustainable careers in organizations. In A. De Vos \& B.I.J.M. Van der Heijden (Eds.), Handbook of research on sustainable career, (pp. 20-34). Edward Elgar Publishing Limited. https://doi.org/10.4337/9781782547037.00007

Van der Heijden, B. I. J. M., \& De Vos A. (2015). Sustainable careers: introductory chapter. In A. De Vos \& B.I.J.M. Van der Heijden (Eds.), Handbook of research on sustainable career, (pp. 1-19). Edward Elgar Publishing Limited. https://doi.org/10.4337/9781782547037.00006

Wilson, E. J. (2008). Hard power, soft power, smart power. The Annals of the American Academy of Political and Social Science, 616(1), 110-124. https://doi.org/10.1177/0002716207312618

World Commission on Environment and Development [Brundtland komisija] (1987). Report of the World Commission on Environment and Development: Our Common Future. [2014-11-15]. http://www.un-documents.net/our-commonfuture.pdf

Wright, P. M., Gardner, T. M., Moynihan, L. M., \& Allen, M. R. (2005). The relationship between HR practices and firm performance: Examining causal order. Personnel Psychology, 58, 409-446. https://doi.org/10.1111/j.17446570.2005.00487.x

Zaugg, R. J. (2009). Nachhaltiges Personalmanagement: Eine neue Perspektive und empirische Exploration des Human Resource Management. Wiesbaden: Gabler. https://doi.org/10.1007/978-3-8349-8443-2

Zaugg, R. J., Blum, A., \& Thom, N. (2001). Sustainability in human resource management. Evaluation report. Berne: IOPPress.

Zink, K. J. (2014). Designing sustainable work systems: the need for a systems approach. Applied Ergonomics, 45, 126132. https://doi.org/10.1016/j.apergo.2013.03.023

The article has been reviewed.

Received in February, 2017; accepted in April, 2017. 